\title{
Both Debridement and Microfracture Produce Excellent Results for Osteochondritis Dissecans Lesions of the Capitellum: A Systematic Review
}

\author{
Richard J. McLaughlin, M.D., Devin P. Leland, M.D., Christopher D. Bernard, M.D., \\ Joaquin Sanchez-Sotelo, M.D., Ph.D., Mark E. Morrey, M.D., \\ Shawn W. O’Driscoll, M.D., Ph.D., and Christopher L. Camp, M.D.
}

\begin{abstract}
Purpose: To analyze the available literature pertaining to the indications, outcomes, and complications of both microfracture (MFX) and simple debridement for capitellar osteochondritis dissecans (OCD). Methods: A comprehensive literature review was conducted according to Preferred Reporting Items for Systematic Reviews and Meta-analyses (PRISMA) criteria. Studies were included if they evaluated OCD of the capitellum that underwent either arthroscopic debridement (AD) or MFX. The risk of bias was assessed using the Methodological Index for Non-randomized Studies (MINORS) scale. Patient demographic characteristics, imaging findings, return-to-sport rates, patient-reported outcomes, range of motion (ROM), complications, failures, and reoperations were recorded. Results: Eleven studies with 327 patients ( 332 elbows) met the inclusion criteria. Methodological Index for Non-randomized Studies (MINORS) scores ranged from $63 \%$ to $75 \%$ and showed considerable heterogeneity. Both AD and MFX showed improvement in patient outcome scores, ROM, and return to play, although the data precluded relative conclusions. Improvement in motion after MFX ranged from $4.9^{\circ}$ to $5^{\circ}$ of flexion, $5^{\circ}$ to $22.6^{\circ}$ of extension, $1^{\circ}$ to $2^{\circ}$ of pronation, and $0.5^{\circ}$ to $2^{\circ}$ of supination, whereas after $\mathrm{AD}$, it ranged from $-4^{\circ}$ to $6^{\circ}$ of flexion and $-0.4^{\circ}$ to $14^{\circ}$ of extension, with prono-supination noted in only 1 study. The rate of return to play at a similar level of preinjury athletic competition ranged from $55 \%$ to $75 \%$ after MFX and from $40 \%$ to $100 \%$ after $\mathrm{AD}$. Lesion location was discussed in only 1 study. Postoperative imaging trended toward early degenerative changes, most commonly of the radial head. Complications were only reported in l MFX study; in all cases, the complication was transient ulnar nerve neurapraxia. Reoperation rates ranged from $0 \%$ to $10 \%$, and reoperation was most commonly performed to address radial head enlargement. Five studies reported no reoperations. Conclusions: Both AD and MFX for capitellar OCD appear to yield excellent improvements in pain, ROM, patient outcome scores, and return to sport. Given that comparable mid-term outcomes can be achieved with debridement alone, without the use of MFX, similarly to recent prospective studies in the knee, AD alone may be a reasonable approach to relatively small OCD defects. Level of Evidence: Level IV, systematic review of studies, all Level IV evidence.
\end{abstract}

From the Department of Orthopedics, Mayo Clinic Sports Medicine Center, Rochester, Minnesota, U.S.A.

The authors report the following potential conflicts of interest or sources of funding: J.S-S. is a board or committee member of American Academy of Orthopaedic Surgeons and American Shoulder and Elbow Surgeons; is a paid presenter or speaker for Acumed, Arthrex, and Stryker; receives publishing royalties and financial or material support from Elsevier, Journal of Shoulder and Elbow Surgery, Merck Sharp $\theta$ Dohm, and Oxford University Press; is a pain consultant for Exactech; receives hospitality payments from Gemini Medical and Tornier; is on the editorial or governing board of Journal of Orthopaedics and Traumatology, Journal of Shoulder and Elbow Surgery, and Merck Sharp $\theta$ Dohm; receives intellectual property royalties from Stryker; receives research support from Stryker; receives consulting fees from Tornier; receives travel and lodging support from Tornier; and is a paid consultant for Wright Medical Technology, outside the submitted work. M.E.M. owns stock or stock options in Tenex and receives personal fees for education from Zimmer Biomet Holdings and Arthrex, outside the submitted work. S.W.O. receives intellectual property royalties from Acumed,
Aircast, and Wright Medical Technology; receives research support from Acumed and Wright Medical Technology; is an unpaid consultant for Acumed; and is a paid presenter or speaker for Wright Medical Technology, outside the submitted work. C.L.C. receives hospitality payments from Arthrex and Zimmer Biomet and receives educational support from Arthrex, outside the submitted work. Full ICMJE author disclosure forms are available for this article online, as supplementary material.

Received April 13, 2020; accepted October 16, 2020.

Address correspondence to Christopher L. Camp, M.D., Mayo Clinic, 200 First St SW, Rochester, MN 55905,U.S.A. E-mail: Camp.christopher@mayo. edu

(C) 2020 THE AUTHORS. Published by Elsevier Inc. on behalf of the Arthroscopy Association of North America. This is an open access article under the CC BY-NC-ND license (http://creativecommons.org/licenses/by-nc-nd/4.0/). 2666-061X/20520

https://doi.org/10.1016/j.asmr.2020.10.002 
$\mathbf{O}$ steochondritis dissecans (OCD) lesions of the humeral capitellum are a well-known source of substantial morbidity in the upper extremity ${ }^{1}$ and are most commonly found in repetitive overhead athletes and gymnasts ${ }^{2,3}$; although OCD lesions can occur anywhere within the elbow joint, most are found at the humeral capitellum. ${ }^{1,4}$ It is thought that such lesions are the result of repetitive axial and valgus contact pressures at the radiocapitellar joint ${ }^{5}$ in an individual with a genetic predisposition at a watershed region of the humeral articular cartilage. ${ }^{6-8}$ Given this mechanism, it is not surprising that both adolescent baseball players and competitive gymnasts show the highest incidence of capitellar OCD because both activities require such contact pressures. ${ }^{4,9,10}$ The capitellar OCD prevalence has been reported at $1 \%$ to $7 \%$ in the adolescent baseball population, ${ }^{9,11}$ with a reported incidence of 3.4 in 100,000 among 12- to 19-year-old adolescents, reflecting an overwhelming male predominance. ${ }^{4}$ Capitellar OCD lesions are typically classified as either stable or unstable based on the stability of the fragment involved and the presence or absence of mechanical symptoms. ${ }^{12-14}$ Current treatment options for capitellar OCD lesions include both nonoperative and operative treatment modalities, with surgical management recommended for unstable and symptomatic lesions. ${ }^{13,14}$ "Reparative" techniques, such as arthroscopic debridement (AD) and microfracture (MFX), do not involve a surgical attempt at restoration of the subchondral bone and hyaline articular cartilage surface. Conversely, "restorative" techniques, such as osteochondral autograft transfer, osteochondral allograft transplantation, and autologous chondrocyte implementation, ${ }^{14,15}$ do involve such an attempt and accomplish this through various procedures.

Although considerable attention has been given to the surgical management of capitellar OCD lesions in the recent literature, important unanswered questions remain with respect to the ideal surgical treatment and patient selection criteria., 11,14,16-20 Both reparative and restorative techniques for capitellar OCD lesions have paralleled-and originated from-treatment modalities uses for cartilage defects in the knee. ${ }^{21}$ With respect to humeral capitellar OCD, restorative surgical options have recently been popularized and associated with promising mid-term outcomes, ${ }^{16}$ but the relatively increased time away from sport 2,17 and the potential for donor-site morbidity ${ }^{17,22}$ are complications that would suggest using reparative techniques in patients who meet the appropriate criteria.

Although AD and MFX are the most commonly used reparative techniques, the specific indications for which MFX should be used as opposed to debridement remains unclear. Whereas many surgeons are beginning to favor debridement over MFX for knee cartilage injuries, ${ }^{23}$ it is unclear if this is also true for the capitellum. The purpose of this systematic review was to analyze the available literature pertaining to the indications, outcomes, and complications of both MFX and simple debridement for capitellar OCD. It was hypothesized that overall patient improvement would occur after both MFX and AD for the treatment of capitellar OCD.

\section{Methods}

\section{Literature Search}

A comprehensive search of the available literature was performed on November 30, 2018, according to the Preferred Reporting Items for Systematic Reviews and Meta-analyses (PRISMA) guidelines (Fig 1). ${ }^{24}$ The databases searched included PubMed (MEDLINE), the Cochrane Register of Controlled Trials and the Cochrane Library, and the Cumulative Index for Nursing and Allied Health Literature (CINAHL). The timeline for search parameters was set from database inception to November 30, 2018. A Boolean algebra search was used as follows: (microfracture OR debridement OR drilling) AND (elbow OR capitellum OR capitellar) AND (osteochondritis dissecans OR OCD). Duplicate and non-English-language articles were removed, and the remaining articles underwent title and abstract screening (Fig 1).

\section{Selection Criteria}

Titles and abstracts were reviewed by 2 independent authors (R.J.M. and D.P.L.), and studies that were eliminated in consensus were removed from the database. Any disagreements were resolved via consensus discussion between the reviewers and the senior author (C.L.C.). Records excluded during the process of title and abstract screening included animal or cadaveric studies, non-capitellar studies, nonsurgical studies, systematic reviews, technique articles, case reports, and review articles (Fig 1). After this screening process, the remaining full texts were manually reviewed for inclusion.

The inclusion criteria were osteochondral defects of the capitellum that had been treated with MFX or debridement. The exclusion criteria included fixation, osteochondral allograft transplantation, osteochondral autograft transfer (OAT), and autologous chondrocyte implementation techniques. If a study included several types of surgical techniques including MFX or debridement but it could not be determined which surgical procedure was performed on which patients (and associated outcomes), the entire study was excluded. After this review of full texts, the remaining studies were ultimately included in our systematic review (Fig 1). 
Fig 1. Study flowchart. (ACI, autologous chondrocyte implementation; CINHAL, Cumulative Index for Nursing and Allied Health Literature; OCA, osteochondral allograft transplantation; OAT, osteochondral autograft transfer.)
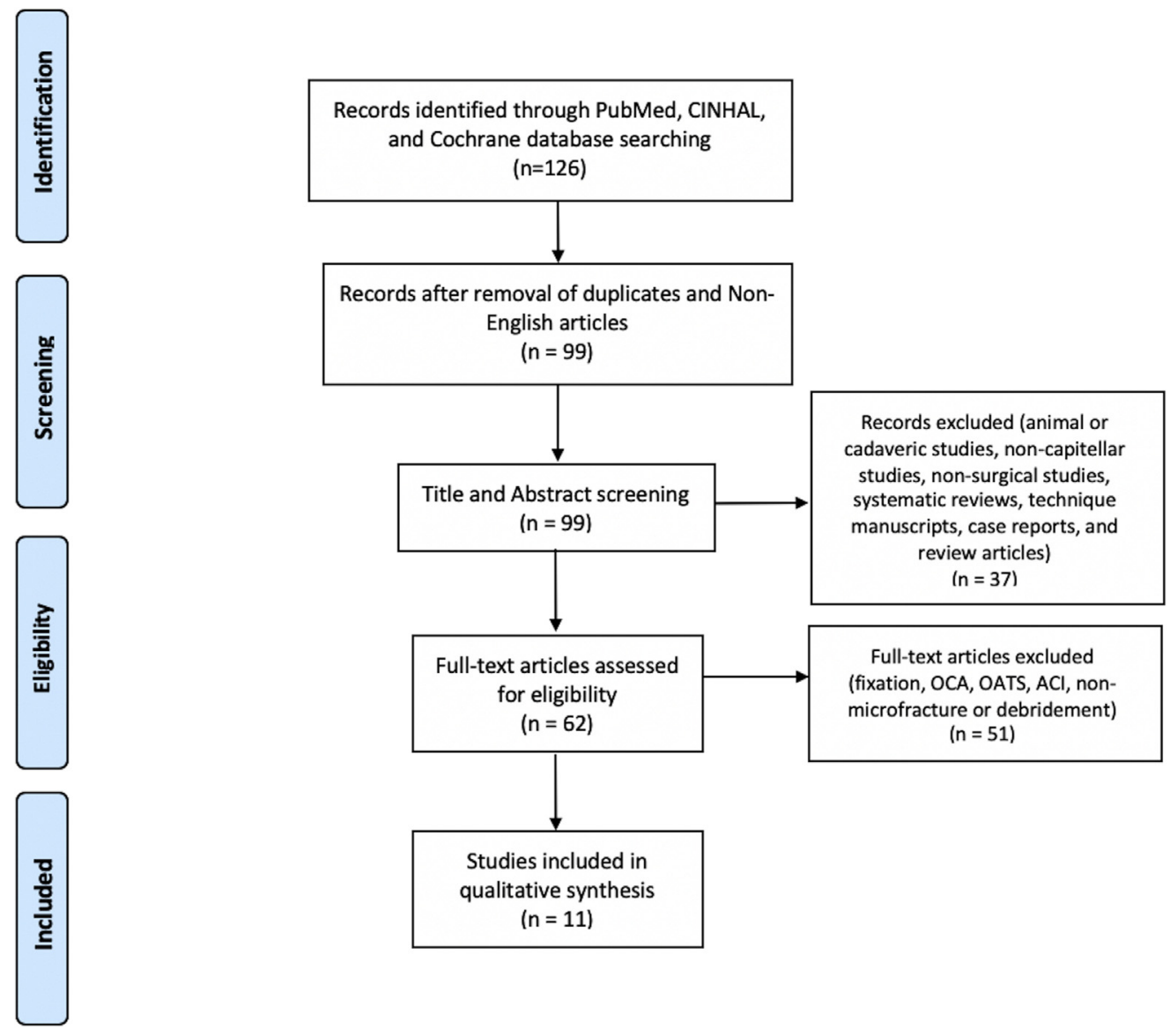

\section{Quality Assessment}

Because no randomized controlled trials or comparative studies were found in the literature search, each study was critically assessed for quality using the Methodological Index for Non-randomized Studies (MINORS) scoring system. ${ }^{25}$ The MINORS system has been shown to be a validated tool created to assess the quality of nonrandomized surgical studies, with a maximum score of 16 for noncomparative studies (8item checklist scored from 0-2) and 24 for comparative studies (12-item checklist scored from 0-2). As a result, higher MINORS scores represent a lower level of bias. The 11 studies were scored independently by 2 reviewers (R.J.M. and D.P.L.), with any disagreements resolved in a consensus discussion with the senior author (C.L.C.) when necessary. The level of evidence was determined according to the Oxford Centre for Evidence-based Medicine.

\section{Data Analysis}

Studies were reviewed, and the data extracted included study properties (year, level of evidence, number of patients), patient demographic characteristics (age, dominant arm, skeletal maturity, follow-up), surgical details, outcomes (return to sport [RTS], patient-reported outcomes, range of motion [ROM], imaging), mean follow-up intervals, complications, failures, and reoperations. Because of the lack of comparative studies and the resulting heterogeneity in reported outcomes, data were not pooled and were instead reported as ranges to avoid inaccurate reporting. ${ }^{26}$ All data were analyzed using Microsoft Excel (2010; Microsoft, Redmond, WA) and JMP Pro software (version 14.1.0 [2018]; SAS Institute, Cary, NC). Forest plots were created using Microsoft Excel, and $95 \%$ confidence intervals were calculated for the percentage RTS according to the adjusted Wald method. ${ }^{27}$

\section{Results}

\section{Study Selection}

The initial search resulted in 90 articles from PubMed, 36 articles from the Cumulative Index for Nursing and Allied Health Literature (CINAHL), and 0 articles from the Cochrane Library (Fig 1). After application of the inclusion and exclusion criteria, a total of 9 studies remained. Review of the references of the remaining studies was subsequently performed and yielded 2 additional publications, for a total of 11 studies. 


\section{Study Characteristics}

Full details regarding the individual study characteristics are presented in Table 1. Three studies, all Level IV retrospective case series published between 2012 and 2017, evaluated MFX for the treatment of capitellar OCD lesions. ${ }^{23,28,29}$ These studies encompassed 94 elbows in 90 patients, with the rate of involvement of the dominant extremity ranging from $56 \%$ to $80 \%$. The mean patient age ranged from 13.9 to 16 years (overall range, 10.8-26 years), and the mean follow-up period ranged from 3.5 to 5.3 years (overall range, 1-9 years). The lesion grade was reported in all 3 studies, with 2 studies reporting median Baumgarten grades of $5^{23}$ and $4^{28}$ and the last study reporting a median International Cartilage Repair Society (ICRS) score of IV. ${ }^{29}$ Conversely, AD was evaluated in 8 studies, including 7 Level IV retrospective case series and 1 prospective case series, all published between 1998 and $2017 .^{30-37}$ These studies included 238 elbows in 237 patients, with the dominant extremity involved in $47 \%$ to $100 \%$ of patients as reported in 5 of 8 studies; 3 studies did not report hand dominance. The mean patient age ranged from 13.6 to 28 years (overall range, 8-49 years), and the average follow-up period ranged from 1.1 to 8 years (overall range, 0.7-12.4 years). Seven studies reported on lesion grade using a total of 4 different classifications, with lesions overall trending toward intermediate- or high-grade lesions (Table 1). The mean MINORS score for all included studies as a normalized percentage was 69\% (range, 63\%-75\%). Of the studies, $5(45 \%)$ were performed in the United States whereas the remainder were performed in Europe $(36 \%)$ and Japan (18\%).

\section{Outcomes}

Satisfaction. Patient satisfaction was reported in 2 studies, both of which involved AD cohorts. Brownlow et al. ${ }^{32}$ measured postoperative patient satisfaction and found a mean score of 8.6 (range, 4-10) out of 10, whereas an additional study reported that "excellent" pain relief was found in 11 of 12 patients at a mean final follow-up of 3.2 years. ${ }^{35}$

Outcome Measures. Various patient-reported outcome measures were reported in 7 of the 11 studies, with an overall trend toward improvement in both MFX patients and $\mathrm{AD}$ patients postoperatively (Table 2). All 3 MFX studies reported outcome measures. The Oxford Elbow Score was reported in 1 study, in which the mean postoperative score was 40.8 (standard deviation, 8.0). ${ }^{23}$ The remaining 2 MFX studies reported both preoperative and postoperative Mayo Elbow Performance Scores or Mayo Elbow Performance Index scores, with the first finding average improvement from 53.3 to $98.3^{28}$ and the second reporting average improvement from 70.5 to $97 .^{29}$ The latter study also reported an improvement in the mean TimmermanAndrews Elbow Score from 116 preoperatively to 193 postoperatively, and notably, all patients reported postoperative scores greater than $180 .^{29}$ Of the $8 \mathrm{AD}$ studies, 4 included patient-reported outcome measures, although notably different measures were used. One study reported postoperative Mayo Elbow Performance Index and Elbow Functional Rating Index scores and found them to be excellent in 9 patients, good in 8 , and fair in $1 .^{32}$ An additional study reported the Modified Andrews Elbow Scoring System and found a statistically significant improvement postoperatively, with a mean score of $90.8 .^{30}$ Finally, $2 \mathrm{AD}$ studies reported Disabilities of the Arm, Shoulder and Hand scores, with the first reporting a mean postoperative score of 8.6 (range, 0-22.4), ${ }^{36}$ whereas the second noted an average change from 47.7 preoperatively to 3 postoperatively. ${ }^{37}$ Ueda et al. ${ }^{37}$ additionally reported the Japanese Orthopaedic Association-Japan Elbow Society score and found a statistically significant improvement from 62.7 preoperatively to 92.3 postoperatively.

Range of Motion. ROM was evaluated in 7 studies (Table 2). Two MFX studies reported ROM, and both found an overall statistically significant improvement in extension but not supination or pronation. ${ }^{23,29}$ Only 1 study reported a statistically significant improvement in flexion, from a mean of $134^{\circ}$ preoperatively to $139^{\circ}$ postoperatively. ${ }^{23}$ Overall, after MFX, the mean reported postoperative ROM improvement ranged from $4.9^{\circ}$ to $5^{\circ}$ of flexion, $5^{\circ}$ to $22.6^{\circ}$ of extension, $1^{\circ}$ to $2^{\circ}$ of pronation, and $0.5^{\circ}$ to $2^{\circ}$ of supination. ${ }^{23,29} \mathrm{AD}$ studies reported ROM that similarly reflected an overall postoperative improvement, although notably, only 1 study reported prono-supination. ${ }^{30,31,34,35,37}$ Baumgarten et al. ${ }^{31}$ reported an improvement in mean flexion contracture from $19^{\circ}$ to $5^{\circ}$ postoperatively and an improvement in mean extension contracture from $12^{\circ}$ to $6^{\circ}$ postoperatively, without commenting on statistical significance. Miyake and Masatomi ${ }^{34}$ reported a statistically significant postoperative improvement in mean flexion contracture from $8^{\circ}$ to $5^{\circ}$. Ruch et al. ${ }^{35}$ found that the mean arc of motion improved from $110^{\circ}$ preoperatively to $127^{\circ}$ postoperatively, with an improvement in mean flexion contracture from $23^{\circ}$ to $11^{\circ}$. An additional study reported statistically significant postoperative improvement in both flexion (from $133^{\circ}$ to $137^{\circ}$ ) and extension (from $-13^{\circ}$ to $1^{\circ}$ ). ${ }^{37}$ It is interesting to note that the final study reported overall postoperative decreases in flexion, extension, pronation, and supination, but notably, none met the threshold of statistical significance. ${ }^{30}$ Overall, after $\mathrm{AD}$, the mean reported postoperative improvement in flexion ranged from $-4^{\circ}$ to $6^{\circ}$ and that in extension ranged from $-0.4^{\circ}$ to $14^{\circ}$. $^{30,31,34,35,37}$ 
Table 1. Demographic Characteristics of Included Studies $(\mathrm{N}=11)$

\begin{tabular}{|c|c|c|c|c|c|c|c|c|c|}
\hline Study & $\begin{array}{l}\text { MINORS } \\
\text { Score, \% }\end{array}$ & LOE & $\begin{array}{l}\text { Treatment } \\
\text { Type }\end{array}$ & $\begin{array}{l}\text { No. of } \\
\text { Patients }\end{array}$ & $\begin{array}{l}\text { Dominant Arm } \\
\text { Involvement, } \mathrm{n}(\%)\end{array}$ & $\begin{array}{c}\text { Skeletal } \\
\text { Maturity, n }\end{array}$ & $\begin{array}{c}\text { Grade or } \\
\text { Classification, } \mathrm{n}\end{array}$ & $\begin{array}{l}\text { Mean Age } \\
\text { (Range), yr }\end{array}$ & $\begin{array}{l}\text { Mean Follow-up } \\
\text { (Range), yr }\end{array}$ \\
\hline $\begin{array}{l}\text { Bexkens et al. }{ }^{23} \\
(2017)\end{array}$ & 69 & Level IV, RCS & MFX & 71 (75 elbows) & $57(76)$ & $\begin{array}{c}\text { IM: } 12 \\
\text { M: } 63\end{array}$ & $\begin{array}{c}\text { Baumgarten } \\
\text { Grade 1:3 } \\
\text { Grade 2: } 2 \\
\text { Grade 3: } 10 \\
\text { Grade 4: } 1 \\
\text { Grade 5: } 59\end{array}$ & $16(11-26)$ & $3.5(1-8.2)$ \\
\hline $\begin{array}{l}\text { Bojanic et al. } \\
\quad(2012)\end{array}$ & 69 & Level IV, RCS & MFX & 9 & $5(56)$ & $\begin{array}{l}\text { IM: } 3 \\
\text { M: } 6\end{array}$ & $\begin{array}{l}\text { Baumgarten } \\
\text { Grade } 3: 3 \\
\text { Grade } 4: 4 \\
\text { Grade } 5: 2\end{array}$ & $15(12-19)$ & $5.3(2-9)$ \\
\hline Wulf et al. ${ }^{29}$ (2012) & 75 & Level IV, RCS & MFX & 10 & $8(80)$ & $\begin{array}{l}\text { IM: } 7 \\
\text { M: } 3\end{array}$ & $\begin{array}{l}\text { ICRS } \\
\text { III: } 2 \\
\text { IV: } 8\end{array}$ & $13.9(10.8-18.5)$ & $3.5(2.3-4.5)$ \\
\hline $\begin{array}{l}\text { Baumgarten et al. } \\
\text { (1998) }\end{array}$ & 63 & Level IV, RCS & Debridement & 16 (17 elbows) & $15(88)$ & NR & $\begin{array}{l}\text { Baumgarten } \\
\text { Grade 2: } 1 \\
\text { Grade 3: } 3 \\
\text { Grade 4: } 5 \\
\text { Grade 5: } 8\end{array}$ & $13.8(10-17)$ & $4(2-8.3)$ \\
\hline $\begin{array}{l}\text { Brownlow et al. }{ }^{32} \\
\text { (2006) }\end{array}$ & 63 & Level IV, RCS & Debridement & 29 & $16(55)$ & NR & NR & $22(11-49)$ & $6.4(0.6-12.4)$ \\
\hline Byrd et al. ${ }^{33}$ (2001) & 69 & Level IV, RCS & Debridement & 8 & $8(100)$ & IM: 8 & $\begin{array}{l}\text { ASMI } \\
\text { II: } 1 \\
\text { IV: } 2 \\
\text { V: } 5\end{array}$ & $13.6(11-16)$ & $4(3-6)$ \\
\hline $\begin{array}{l}\text { Miyake and } \\
\text { Masatomi } \\
\text { (2011) }\end{array}$ & 69 & Level IV, RCS & Debridement & 106 & NR & $\begin{array}{l}\text { IM: } 12 \\
\text { M: } 94\end{array}$ & $\begin{array}{c}\text { Takahara } \\
\text { SMo: } 8 \\
\text { SMc: } 85 \\
\text { Lo: } 4 \\
\text { Lc: } 9\end{array}$ & $15(12-18)$ & $1.1(0.7-3.8)$ \\
\hline $\begin{array}{l}\text { Rahusen et al. }{ }^{30} \\
(2006)\end{array}$ & 69 & Level IV, PCS & Debridement & 15 & $7(47)$ & NR & $\begin{array}{l}\text { Baumgarten } \\
\text { Grade 3: } 6 \\
\text { Grade 4: } 5 \\
\text { Grade 5: } 4\end{array}$ & $28(16-49)$ & $3.8(1.5-4.9)$ \\
\hline Ruch et al. ${ }^{35}$ (1998) & 75 & Level IV, RCS & Debridement & 12 & NR & NR & $\begin{array}{l}\text { Stage II: } 5 \\
\text { Stage III: } 7\end{array}$ & $14.5(8-18)$ & $3.2(2.2-5.9)$ \\
\hline $\begin{array}{l}\text { Schoch and Wolf } \\
\text { (2010) }\end{array}$ & 63 & Level IV, RCS & Debridement & 13 & $12(92)$ & NR & $\begin{array}{l}\text { ASMI } \\
\text { I: } 2 \\
\text { II: } 3 \\
\text { III: } 1 \\
\text { IV: } 1 \\
\text { V: } 6\end{array}$ & $16(10-25)$ & $3.6(1-8)$ \\
\hline Ueda et al. ${ }^{37}$ (2017) & 75 & Level IV, RCS & Debridement & 38 & NR & $\begin{array}{r}\text { IM: } 38 \\
\text { M: } 0\end{array}$ & $\begin{array}{l}\text { Takahara } \\
\text { Grade III }\end{array}$ & $14(13-15)$ & $8(5-12)$ \\
\hline
\end{tabular}

ASMI, American Sports Medicine Institute; ICRS, International Cartilage Repair Society; IM, immature; Lc, large lesion with closed physis; Lo, large lesion with open physis; LOE, level of evidence; M, mature; MFX, microfracture; MINORS, Methodological Index for Non-randomized Studies; NR, not reported; PCS, prospective case series; RCS, retrospective case series; SMc, small or moderate lesion with closed physis; SMo, small or moderate lesion with open physis. 
Table 2. Reported Patient Outcomes

\begin{tabular}{|c|c|c|c|c|}
\hline Study & $\begin{array}{c}\text { Patient-Reported Outcome } \\
\text { Measures }\end{array}$ & ROM (Preop vs Postop) & Return to Sport & Imaging Results \\
\hline $\begin{array}{l}\text { Bexkens } \\
\text { et } \text { al. }^{23} \\
(2017)\end{array}$ & $\begin{array}{l}\text { Mean OES } \\
\text { Postop: } 40.8 \\
\text { Independent predictors of } \\
\text { higher OES } \\
\text { Open physis }(P=.025) \\
\text { Loose body removal }(P= \\
\text {.0020) } \\
\text { Shorter duration of Preop } \\
\text { symptoms }(P=.029)\end{array}$ & $\begin{array}{l}\text { Mean flexion: } 134^{\circ} \text { vs } 139^{\circ}(P \\
<.001) \\
\text { Mean extension deficit: } 8^{\circ} \\
\text { vs } 3^{\circ}(P<.001) \\
\text { Mean pronation: } 77^{\circ} \text { vs } 78^{\circ} \\
(P=.47) \\
\text { Mean supination: } 78^{\circ} \text { vs } 80^{\circ} \\
(P=.065)\end{array}$ & $\begin{array}{l}\text { Same or higher level: } 55 \% \\
\text { Lower level: } 7 \% \\
\text { No return because of } \\
\text { elbow: } 25 \% \\
\text { No return because of } \\
\text { other reasons: } 13 \%\end{array}$ & NR \\
\hline $\begin{array}{l}\text { Bojanic et al. } \\
\text { (2012) }\end{array}$ & $\begin{array}{l}\text { Mean MEPI } \\
\text { Preop: } 53.3 \\
\text { Postop: } 98.3\end{array}$ & NR & $\begin{array}{l}\text { Same or higher level: } 66 \% \\
\text { Lower level: } 11 \% \\
\text { Changed sport } \\
\text { (unrelated to elbow): } \\
22 \%\end{array}$ & NR \\
\hline $\begin{array}{l}\text { Baumgarten } \\
\text { et al. } \\
\text { (1998) }\end{array}$ & NR & $\begin{array}{l}\text { Mean flexion contracture: } 19^{\circ} \\
\text { vs } 5^{\circ} \\
\text { Mean extension } \\
\text { contracture: } 12^{\circ} \text { vs } 6^{\circ}\end{array}$ & $\begin{array}{l}\text { Same level: } 82 \% \\
\text { Change or cessation of } \\
\text { sport: } 18 \%\end{array}$ & $\begin{array}{l}\text { Radiography } \\
\text { Flattening of capitellum: } 8 \\
\text { elbows } \\
\text { Questionable loose bodies: } 2 \\
\text { patients } \\
\text { No degenerative arthritis or } \\
\text { myositis ossificans }\end{array}$ \\
\hline $\begin{array}{l}\text { Byrd et al. } \\
\text { (2002) }\end{array}$ & $\begin{array}{c}\text { Mean Postop subjective score } \\
97.5 \text { (range, } 90-100 \text { ) }\end{array}$ & NR & $\begin{array}{l}\text { Same level: } 50 \% \\
\text { Change or cessation of } \\
\text { sport: } 50 \%\end{array}$ & $\begin{array}{l}\text { Radiography } \\
\text { Normal: } 63 \% \text { (5 of } 8 \text { ) } \\
\text { Lesion still evident: } 13 \% \text { (1 of } \\
8 \text { ) } \\
\text { Secondary degenerative } \\
\text { changes: } 13 \%(1 \text { of } 8 \text { ) } \\
\text { Lesion still evident and } \\
\text { secondary degenerative } \\
\text { changes: } 13 \% \text { ( } 1 \text { of } 8 \text { ) }\end{array}$ \\
\hline $\begin{array}{l}\text { Miyake and } \\
\text { Masatomi }^{34} \\
\text { (2011) }\end{array}$ & $\begin{array}{l}\text { Elbow pain Preop vs Postop } \\
\text { (No. of patients) } \\
\text { None: } 0 \text { vs } 89 \\
\text { Mild: } 36 \text { vs } 15 \\
\text { Moderate or severe: } 70 \text { vs } \\
2\end{array}$ & $\begin{array}{l}\text { Mean flexion: } 133^{\circ} \text { vs } 135^{\circ} \\
(P=.07) \text { (if small lesion } \\
\text { with closed physis group, } \\
P=.04) \\
\text { Mean flexion contracture: } \\
8^{\circ} \text { vs } 5^{\circ}(P=.03)\end{array}$ & $\begin{array}{l}\text { Same level: } 85 \% \\
\text { Lower level: } 4 \% \\
\text { Change or cessation of } \\
\text { sport: } 11 \%\end{array}$ & $\begin{array}{l}\text { Radiography } \\
\text { Remodeling: } 12 \% \text { (13 of 106) } \\
\text { Unchanged: } 81 \% \text { ( } 86 \text { of 106) } \\
\text { Radial head enlargement: } 7 \% \\
\text { (7 of 106) } \\
\text { OA changes of radiocapitellar } \\
\text { joint: } 3 \% \text { ( } 3 \text { of } 106 \text { ) } \\
\text { NOTE. All large lesions with } \\
\text { closed physes had radial head } \\
\text { enlargement. }\end{array}$ \\
\hline
\end{tabular}


Table 2. Continued

\begin{tabular}{|c|c|c|c|c|}
\hline Study & $\begin{array}{c}\text { Patient-Reported Outcome } \\
\text { Measures }\end{array}$ & ROM (Preop vs Postop) & Return to Sport & Imaging Results \\
\hline $\begin{array}{l}\text { Rahusen } \\
\text { et al. }^{30} \\
(2006)\end{array}$ & $\begin{array}{l}\text { MAESS } \\
\text { Preop: } 65.5 \\
\text { Postop: } 90.8(P<.001) \\
\text { VAS score Preop vs Postop } \\
\text { Rest: } 3 \text { vs } 1 \\
\text { Provocation: } 7 \text { vs } 2(P< \\
\text {.001) }\end{array}$ & $\begin{array}{l}\text { Mean flexion: } 145.3^{\circ} \text { vs } 141.3 \\
\text { (NS) } \\
\text { Mean extension: }-3.3^{\circ} \text { vs } \\
-3.7^{\circ} \text { (NS) } \\
\text { Mean pronation: } 82^{\circ} \text { vs } 80^{\circ} \\
\text { (NS) } \\
\text { Mean supination: } 78.9^{\circ} \text { vs } \\
74.7^{\circ} \text { (NS) }\end{array}$ & Same level: $80 \%$ & $\mathrm{NR}$ \\
\hline $\begin{array}{l}\text { Ruch et al. }{ }^{35} \\
\text { (1998) }\end{array}$ & $\begin{array}{l}\text { Pain } \\
\text { 92\% (11 of } 12) \text { reported } \\
\text { excellent Postop relief } \\
\text { VAS score } \\
\text { Preop: } 6.9 \\
\text { Postop: } 1.8\end{array}$ & $\begin{array}{l}\text { Mean flexion (Postop): } 140^{\circ} \\
\left(120^{\circ}-150^{\circ}\right) \\
\text { Mean extension (Postop): } \\
11^{\circ}\left(-10^{\circ} \text { to } 35^{\circ}\right) \\
\text { Mean arc: } 110^{\circ} \text { vs } 127^{\circ} \\
\text { Mean flexion contracture: } \\
23^{\circ} \text { vs } 11^{\circ}\end{array}$ & $\begin{array}{l}\text { Returned, unknown level: } \\
100 \%(3 \text { of } 3)\end{array}$ & $\begin{array}{l}\text { Radiography } \\
\text { Radial head enlargement: } \\
50 \%(6 \text { of } 12) \\
\text { Lateral capsular fragment: } \\
42 \% \text { ( } 5 \text { of } 12)\end{array}$ \\
\hline $\begin{array}{l}\text { Ueda et al. }{ }^{37} \\
\text { (2017) }\end{array}$ & $\begin{array}{l}\text { Mean JOA-JES score } \\
\text { Preop: } 62.7 \\
\text { Postop: } 92.3(P<.05) \\
\text { Mean DASH score } \\
\text { Preop: } 47.7 \\
\text { Postop: } 3(P<.05)\end{array}$ & $\begin{array}{l}\text { Mean flexion: } 133^{\circ} \text { vs } 137^{\circ} \\
\text { Mean extension: }-13^{\circ} \text { vs } 1^{\circ} \\
(P<.05)\end{array}$ & $\begin{array}{l}\text { Returned, unknown level: } \\
100 \% \text { (38 of } 38 \text { ) }\end{array}$ & $\begin{array}{l}\text { Radiography } \\
\text { Radial head enlargement: } \\
100 \% \text { (38 of } 38 \text { ) } \\
\text { Radial head superior } \\
\text { migration: } 2.6 \% \text { ( } 1 \text { of } 38 \text { ) } \\
\text { Mean Kellgren-Lawrence } \\
\text { grade } \\
\text { Preop: } 1.2 \\
\text { Postop: } 1.5\end{array}$ \\
\hline
\end{tabular}

DASH, Disabilities of the Arm, Shoulder and Hand; EFRI, Elbow Functional Rating Index; JOA-JES, Japanese Orthopaedic Association-Japan Elbow Society; MAESS, Modified Andrews Elbow Scoring System; MEPI, Mayo Elbow Performance Index; MEPS, Mayo Elbow Performance Score; MRI, magnetic resonance imaging; NR, not reported; NS, not significant; OA, osteoarthritis; OES, Oxford Elbow Score; Postop, postoperative; Preop, preoperative; ROM, range of motion; TAES, Timmerman-Andrews Elbow Score; VAS, visual analog scale for pain.

Imaging. Seven studies reported postoperative lesion evaluation with radiographs, which included 1 MFX study and 6 AD studies (Table 2). ${ }^{29,31-35,37}$ The study by Wulf et al., ${ }^{29}$ the only MFX study to report postoperative imaging, evaluated patients with both radiography and magnetic resonance imaging (MRI) at an average of 2.3 years and found mean postoperative improvement in the Takahara grade from 2.1 to 0.7 on radiography and from 3.7 to 1.5 on MRI. All AD studies that reported imaging findings evaluated patients with postoperative radiographs alone. Baumgarten et al. $^{31}$ found radiographic evidence of capitellar flattening in 8 elbows, as well as questionable loose bodies in 2 elbows, but overall no evidence of progressive degenerative disease. Brownlow et al. ${ }^{32}$ similarly noted flattening of the capitellum in 12 patients and loose bodies in 5 patients, with evidence of mild or moderate degenerative changes in 6 patients. One additional study found normal radiographs in 5 of 8 patients $(63 \%)$ and noted evidence of persistent lesions and degenerative changes in the remaining 3 patients. ${ }^{33}$ Miyake and Masatomi ${ }^{34}$ indicated that postoperative radiographs were unchanged in $81 \%$ of patients but found evidence of remodeling in $12 \%$, radial head enlargement in $7 \%$, and degenerative changes in $3 \%$. Regarding the remaining 2 studies, a radial head enlargement rate of $50 \%$ was reported in 1 study ${ }^{35}$ and a mean increase in the Kellgren-Lawrence grade from 1.2 preoperatively to 1.5 postoperatively was found in the other study, with universal radiographic evidence of radial head enlargement in all patients. ${ }^{37}$

Return to Sport. RTS was mentioned in all 11 studies (Table 2), ${ }^{23,28-37}$ although only 7 analyzed whether patients returned to the same level or a higher level of competition (Fig 2). ${ }^{23,28,29,31-34}$ After MFX, the rate of RTS at the same level or a higher level of participation ranged from $55 \%$ to $75 \%$ whereas the rate of return to a lower level or failure to return due to injury ranged from $11 \%$ to $32 \%{ }^{23,28,29}$ Similarly, after $\mathrm{AD}$, the rate of RTS at the same level or a higher level of competition ranged from $40 \%$ to $100 \%$ whereas the rate of return to a lower level or failure to return due to injury ranged from $15 \%$ to $50 \% .^{30-37}$

Complications and Reoperations. Complications were reported in only 1 study in which MFX was performed: 5 of 75 patients $(7 \%)$ experienced transient ulnar nerve neurapraxia postoperatively. ${ }^{23}$ Reoperations were reported in 6 studies, all of which involved AD. ${ }^{31-36}$ 


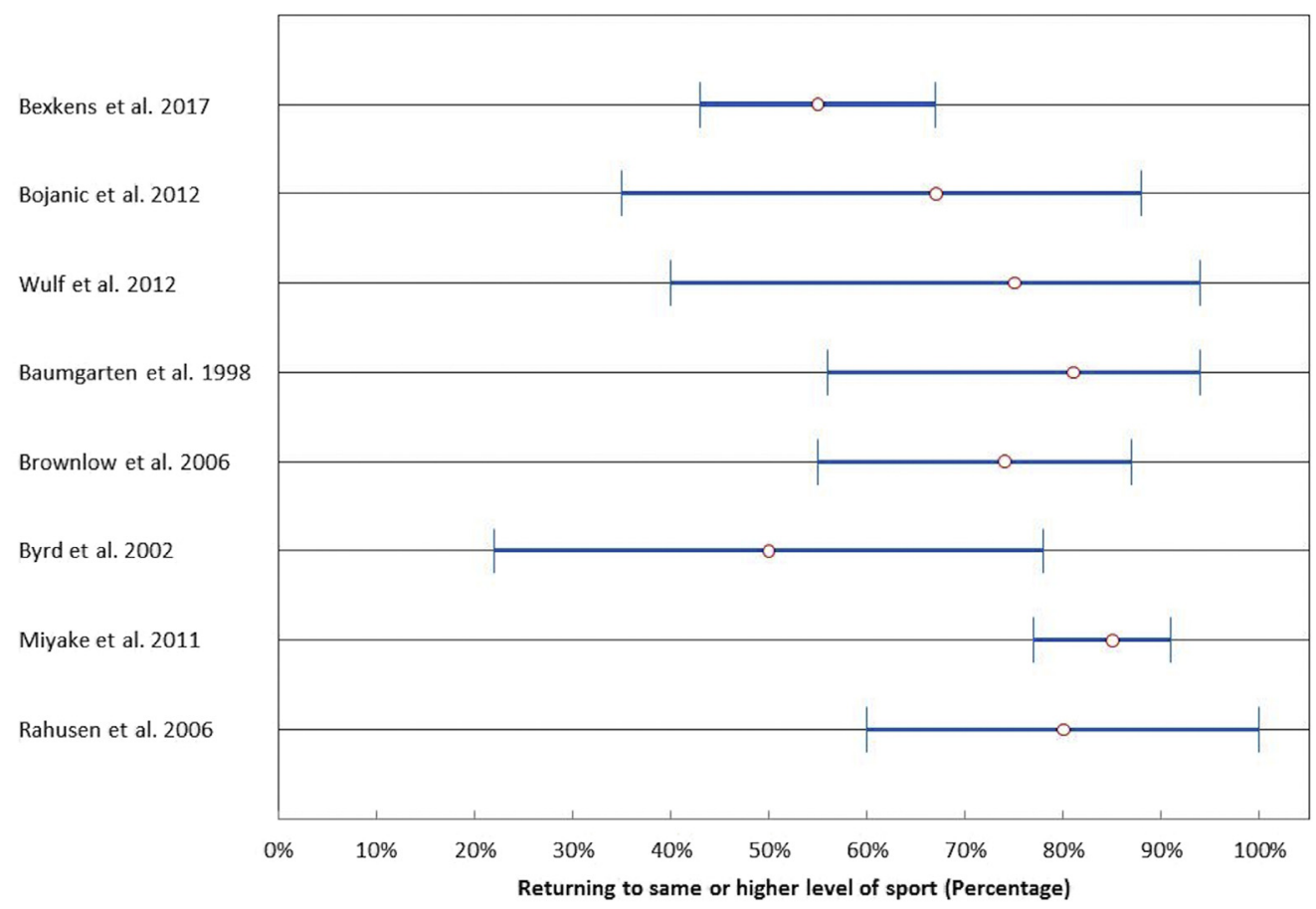

Fig 2. Return to same level or higher level of sport.

The reoperation rate overall ranged from $2 \%$ to $13 \%$ of the patient population, and the reoperations occurred over a reported range of 8 months to 3.8 years, although it is important to note that time to reoperation was explicitly noted in only 4 of 6 studies. Three studies did not mention the specific procedure performed at the time of reoperation, ${ }^{31,33,36}$ whereas radial head resection, posterior arthrotomy with exostosis excision, and repeated arthroscopy to address a persistent lack of extension were reported in the remaining 3 studies. ${ }^{32,34,35}$

\section{Discussion}

Patient improvement was found after either MFX or AD for surgical management of capitellar OCD lesions, although it is important to note that the quality of available research studies, as well as data heterogeneity, makes comparative conclusions difficult. These findings support our hypothesis that patient improvement occurs after both AD and MFX for the treatment of capitellar OCD and there currently exists no discernible difference to support the relative use of either technique. Ultimately, however, additional prospective research studies are needed not only to guide optimal patient- and lesion-specific indications but also to better define long-term outcomes and function.

Although multiple different outcome measures were reported in 7 studies, both MFX and AD appeared to show a relative improvement in postoperative patientreported outcome scores ${ }^{23,28-30,37}$ or reported mean postoperative scores consistent with an excellent outcome. $^{32,36}$ Although ROM was reported in only 2 MFX and 5 AD studies, there was an overall small improvement postoperatively with both techniques (Table 2). An interesting finding was that $1 \mathrm{AD}$ study reported worse postoperative ROM, although it is important to note that this constituted an average of $4.2^{\circ}$ of flexion and $0.4^{\circ}$ of extension. ${ }^{30}$ A notable finding was that after both MFX and AD, there were studies reporting a postoperative improvement of at least $10^{\circ}$ of extension, ${ }^{29,31,35}$ which is important given that patients with capitellar OCD often present with decreased elbow extension.

It is important not only to evaluate the ROM but also to characterize an athlete's return to high-level sport after capitellar OCD. This was reported in 8 of the 11 studies-all MFX studies and 5 of the AD studies. The reported rate of return to the same level (or a higher level) of competition ranged from 50\% to $100 \% .^{23,28-34}$ The remaining 3 studies ${ }^{35-37}$-all AD studies-reported RTS rates ranging from $40 \%$ to $100 \%$, but it is important to note that they did not elucidate the level to which the athletes had returned. When we compared MFX and AD patients, there did appear to be an improved rate of return to play in those treated with $\mathrm{AD}$, although it is important to note that definitive conclusions could not be made. However, these data support similar return-to-play rates after reparative surgical treatment, given that return-to-play rates of $61 \%$ to $100 \%$ have been reported after OATS, a restorative surgical treatment. ${ }^{38,39}$ 
Lesion location and characteristics are important factors to consider prior to surgical intervention of capitellar OCD lesions. Only l study in this literature review reported on patient-specific details regarding lesion location, although it did not comment on whether there was a relation between the location and the rationale for surgical intervention. ${ }^{23}$ Location was not explicitly addressed in the remaining 10 studies. This is an important omission to note because there are now published recommendations that exist in part to guide surgeons on the optimal treatment of elbow OCD. ${ }^{40}$ Camp et al. ${ }^{40}$ recommended debridement for ICRS stage I lesions and MFX for ICRS stage II or III lesions that are $10 \mathrm{~mm}$ in diameter or less with an intact lateral cartilage buttress. Of note, of the 11 studies included in our systematic review, only 1 reported lesion grade using the ICRS staging criteria. ${ }^{29}$

Postoperative imaging including radiography and MRI was reported in 7 studies: 1 MFX study and $6 \mathrm{AD}$ studies. The only MFX study with postoperative imaging reported modest yet incomplete improvement in the Takahara grade at a mean of 2.3 years postoperatively on both radiography and MRI. ${ }^{29}$ All AD studies reported that fewer than $50 \%$ of patients had evidence of degenerative changes at final radiographic follow-up, with the exception of Ueda et al., ${ }^{37}$ who reported that all 38 patients had radiographic evidence of radial head enlargement and a mean KellgrenLawrence grade increase from 1.2 to 1.5. Thus, it would appear that both surgical treatment options have substantial proportions of their populations that show radiographic degenerative changes at mid-term follow-up.

Complications were reported in l study: Bexkens et al. $^{23}$ noted that 5 of 75 patients $(7 \%)$ reported transient ulnar neurapraxia postoperatively; this resolved in all patients. All reoperations were reported in the $\mathrm{AD}$ studies, with rates ranging from $2 \%$ to $13 \%$. The indications for reoperation varied, although 4 studies reported a variant of surgical re-debridement and 2 studies reported radial head resection. As such, albeit with incomplete data, both AD and MFX would appear to be relatively safe surgical procedures with limited complication and reoperation profiles.

\section{Limitations}

This literature review adhered to rigorous established guidelines for systematic reviews. Despite this effort, however, there are weaknesses to this study. This review found a collection of Level IV case-series studies, of which all but 1 were retrospective in nature. Furthermore, it is important to note that not only were these studies unevenly distributed between treatment options-MFX was evaluated in 3 studies whereas AD was evaluated in 8 studies - but also a majority of patients were represented by a single study for each treatment option. ${ }^{23,34}$ This necessarily creates bias, although efforts to report data as a range of means, as opposed to an aggregate number of patients, was performed in large part to mitigate this risk. ${ }^{26}$ Heterogeneity with respect to the reporting of data, especially lesion classification and patient-reported outcome measures, created difficulty when we attempted to compare outcomes and establish general trends or conclusions. Many studies evaluating reparative treatment options were published prior to 2007, and outcomes may have been negatively influenced as a result of this earlier time frame, given that elbow arthroscopy surgical techniques have continued to evolve. ${ }^{41}$ This is in contrast to restorative treatment options, especially OATS, which have received considerable focus in the recent literature, with numerous studies published in the past decade. ${ }^{14}$

\section{Conclusions}

Both AD and MFX for capitellar OCD appear to yield excellent improvements in pain, ROM, patient outcome scores, and RTS. Given that comparable mid-term outcomes can be achieved with debridement alone, without the use of MFX, similarly to recent prospective studies in the knee, ${ }^{42-44} \mathrm{AD}$ alone may be a reasonable approach to relatively small OCD defects.

\section{References}

1. Baker CL III, Romeo AA, Baker CL Jr. Osteochondritis dissecans of the capitellum. Am J Sports Med 2010;38: 1917-1928.

2. Churchill RW, Munoz J, Ahmad CS. Osteochondritis dissecans of the elbow. Curr Rev Musculoskelet Med 2016;9: 232-239.

3. Kajiyama S, Muroi S, Sugaya H, et al. Osteochondritis dissecans of the humeral capitellum in young athletes: Comparison between baseball players and gymnasts. Orthop J Sports Med 2017;5:2325967117692513.

4. Kessler JI, Jacobs JC Jr, Cannamela PC, Weiss JM, Shea KG. Demographics and epidemiology of osteochondritis dissecans of the elbow among children and adolescents. Orthop J Sports Med 2018;6: 2325967118815846.

5. Lu Y, Li YJ, Guo SY, Zhang HL. Is there any difference between open and arthroscopic treatment for osteochondritis dissecans (OCD) of the humeral capitellum: A systematic review and meta-analysis. Int Orthop 2018;42: 601-607.

6. Griffith TB, Kercher J, Clifton Willimon S, Perkins C, Duralde XA. Elbow injuries in the adolescent thrower. Curr Rev Musculoskelet Med 2018;1 1:35-47.

7. Gancarczyk SM, Makhni EC, Lombardi JM, Popkin CA, Ahmad CS. Arthroscopic articular reconstruction of capitellar osteochondral defects. Am J Sports Med 2015;43: 2452-2458.

8. Kobayashi K, Burton KJ, Rodner C, Smith B, Caputo AE. Lateral compression injuries in the pediatric elbow: 
Panner's disease and osteochondritis dissecans of the capitellum. J Am Acad Orthop Surg 2004;12:246-254.

9. Kida Y, Morihara T, Kotoura Y, et al. Prevalence and clinical characteristics of osteochondritis dissecans of the humeral capitellum among adolescent baseball players. Am J Sports Med 2014;42:1963-1971.

10. Otoshi K, Kikuchi S, Kato K, et al. Age-specific prevalence and clinical characteristics of humeral medial epicondyle apophysitis and osteochondritis dissecans: Ultrasonographic assessment of 4249 players. Orthop J Sports Med 2017;5:2325967117707703.

11. Maruyama M, Takahara M, Satake H. Diagnosis and treatment of osteochondritis dissecans of the humeral capitellum. J Orthop Sci 2018;23:213-219.

12. Takahara M, Mura N, Sasaki J, Harada M, Ogino T. Classification, treatment, and outcome of osteochondritis dissecans of the humeral capitellum. J Bone Joint Surg Am 2007;89:1205-1214.

13. Ruchelsman DE, Hall MP, Youm T. Osteochondritis dissecans of the capitellum: Current concepts. J Am Acad Orthop Surg 2010;18:557-567.

14. Logli AL, Bernard CD, O'Driscoll SW, et al. Osteochondritis dissecans lesions of the capitellum in overhead athletes: A review of current evidence and proposed treatment algorithm. Curr Rev Musculoskelet Med 2019;12: $1-12$.

15. Kircher J. Autologous chondrocyte implantation for posttraumatic cartilage defect of the capitulum humeri. J Shoulder Elbow Surg 2016;25:e213-e216.

16. Kirsch JM, Thomas J, Bedi A, Lawton JN. Current concepts: Osteochondritis dissecans of the capitellum and the role of osteochondral autograft transplantation. Hand ( $N$ Y) 2016;11:396-402.

17. Kirsch JM, Thomas JR, Khan M, Townsend WA, Lawton JN, Bedi A. Return to play after osteochondral autograft transplantation of the capitellum: A systematic review. Arthroscopy 2017;33:1412-1420.el.

18. Maruyama M, Takahara M, Harada M, Satake H, Takagi M. Outcomes of an open autologous osteochondral plug graft for capitellar osteochondritis dissecans: Time to return to sports. Am J Sports Med 2014;42:2122-2127.

19. Lewine EB, Miller PE, Micheli LJ, Waters PM, Bae DS. Early results of drilling and/or microfracture for grade IV osteochondritis dissecans of the capitellum. J Pediatr Orthop 2016;36:803-809.

20. Dunn JC, Kusnezov N, Orr J, Mitchell JS. Osteochondral defects of the upper extremity treated with particulated juvenile cartilage transfer. Hand (N Y) 2015;10:683-687.

21. Anderson AF, Lipscomb AB, Coulam C. Antegrade curettement, bone grafting and pinning of osteochondritis dissecans in the skeletally mature knee. Am J Sports Med 1990;18:254-261.

22. Iwasaki N, Kato H, Kamishima T, Suenaga N, Minami A. Donor site evaluation after autologous osteochondral mosaicplasty for cartilaginous lesions of the elbow joint. Am J Sports Med 2007;35:2096-2100.

23. Bexkens R, van den Ende KIM, Ogink PT, van Bergen CJA, van den Bekerom MPJ, Eygendaal D. Clinical outcome after arthroscopic debridement and microfracture for osteochondritis dissecans of the capitellum. Am J Sports Med 2017;45:2312-2318.
24. Moher D, Shamseer L, Clarke M, et al. Preferred reporting items for systematic review and meta-analysis protocols (PRISMA-P) 2015 statement. Syst Rev 2015;4:1.

25. Slim K, Nini E, Forestier D, Kwiatkowski F, Panis Y, Chipponi J. Methodological index for non-randomized studies (MINORS): Development and validation of a new instrument. ANZ J Surg 2003;73:712-716.

26. Cote MP, Lubowitz JH, Rossi MJ, Brand JC. Reviews pooling heterogeneous, low-evidence, high-bias data result in incorrect conclusions: But heterogeneity is an opportunity to explore. Arthroscopy 2018;34:3126-3128.

27. Agresti A, Coull B. Approximate is better than "exact" for interval estimation of binomial proportions. Am Stat 1998;52:119-126.

28. Bojanic I, Smoljanovic T, Dokuzovic S. Osteochondritis dissecans of the elbow: Excellent results in teenage athletes treated by arthroscopic debridement and microfracture. Croat Med J 2012;53:40-47.

29. Wulf CA, Stone RM, Giveans MR, Lervick GN. Magnetic resonance imaging after arthroscopic microfracture of capitellar osteochondritis dissecans. Am J Sports Med 2012;40:2549-2556.

30. Rahusen FT, Brinkman JM, Eygendaal D. Results of arthroscopic debridement for osteochondritis dissecans of the elbow. Br J Sports Med 2006;40:966-969.

31. Baumgarten TE, Andrews JR, Satterwhite YE. The arthroscopic classification and treatment of osteochondritis dissecans of the capitellum. Am J Sports Med 1998;26:520-523.

32. Brownlow HC, O'Connor-Read LM, Perko M. Arthroscopic treatment of osteochondritis dissecans of the capitellum. Knee Surg Sports Traumatol Arthrosc 2006;14: 198-202.

33. Byrd JW, Elrod BF, Jones KS. Elbow arthroscopy for neglected osteochondritis dissecans of the capitellum. J South Orthop Assoc 2001;10:12-16.

34. Miyake J, Masatomi T. Arthroscopic debridement of the humeral capitellum for osteochondritis dissecans: Radiographic and clinical outcomes. J Hand Surg Am 2011;36: 1333-1338.

35. Ruch DS, Cory JW, Poehling GG. The arthroscopic management of osteochondritis dissecans of the adolescent elbow. Arthroscopy 1998;14:797-803.

36. Schoch B, Wolf BR. Osteochondritis dissecans of the capitellum: Minimum 1-year follow-up after arthroscopic debridement. Arthroscopy 2010;26:1469-1473.

37. Ueda Y, Sugaya H, Takahashi N, et al. Arthroscopic fragment resection for capitellar osteochondritis dissecans in adolescent athletes: 5- to 12-year follow-up. Orthop J Sports Med 2017;5:2325967117744537.

38. Westermann RW, Hancock KJ, Buckwalter JA, Kopp B, Glass N, Wolf BR. Return to sport after operative management of osteochondritis dissecans of the capitellum: A systematic review and meta-analysis. Orthop J Sports Med 2016;4:2325967116654651.

39. Bae DS, Ingall EM, Miller PE, Eisenberg K. Early results of single-plug autologous osteochondral grafting for osteochondritis dissecans of the capitellum in adolescents. J Pediatr Orthop 2020;40:78-85.

40. Camp CL, Dines JS, Degen RM, Sinatro AL, Altchek DW. Arthroscopic microfracture for osteochondritis dissecans lesions of the capitellum. Arthrosc Tech 2016;5:e477-e481. 
41. van den Ende KI, McIntosh AL, Adams JE, Steinmann SP. Osteochondritis dissecans of the capitellum: A review of the literature and a distal ulnar portal. Arthroscopy 2011;27:122-128.

42. Bert JM. Abandoning microfracture of the knee: Has the time come? Arthroscopy 2015;31:501-505.

43. Gudas R, Gudaite A, Mickevicius T, et al. Comparison of osteochondral autologous transplantation, microfracture, or debridement techniques in articular cartilage lesions associated with anterior cruciate ligament injury: A prospective study with a 3-year follow-up. Arthroscopy 2013;29:89-97.

44. Gudas R, Gudaite A, Pocius A, et al. Ten-year follow-up of a prospective, randomized clinical study of mosaic osteochondral autologous transplantation versus microfracture for the treatment of osteochondral defects in the knee joint of athletes. Am J Sports Med 2012;40: 2499-2508. 